\title{
Endoscopic management of gastrocolic fistula after endoscopic ultrasound-guided gastrojejunostomy (EUS-G])
}

Endoscopic ultrasound-guided gastrojejunostomy (EUS-GJ) with a lumen-apposing metal stent (LAMS) is a technique used to create a fistula between the stomach and the jejunum with the aim of relieving the symptoms of gastric outlet obstruction (GOO) [1,2]. One of the most feared complications is accidental deployment of the stent into the colon. We describe a patient who developed a delayed gastrocolostomy after EUS-G], which was managed endoscopically.

The patient was a 78-year-old man with an inoperable slowly growing metastatic carcinoid tumor, measuring $6 \mathrm{~cm}$, near the head of the pancreas who developed symptoms of GOO. He was initially treated with EUS-G] with good clinical effect, but after 3 weeks he complained of diarrhea after food intake. He also developed severe malnutrition and dehydration. On follow-up, we found that the distal flange of the LAMS had eroded into the colon to form a gastrocolostomy and it was possible to perform a transgastric

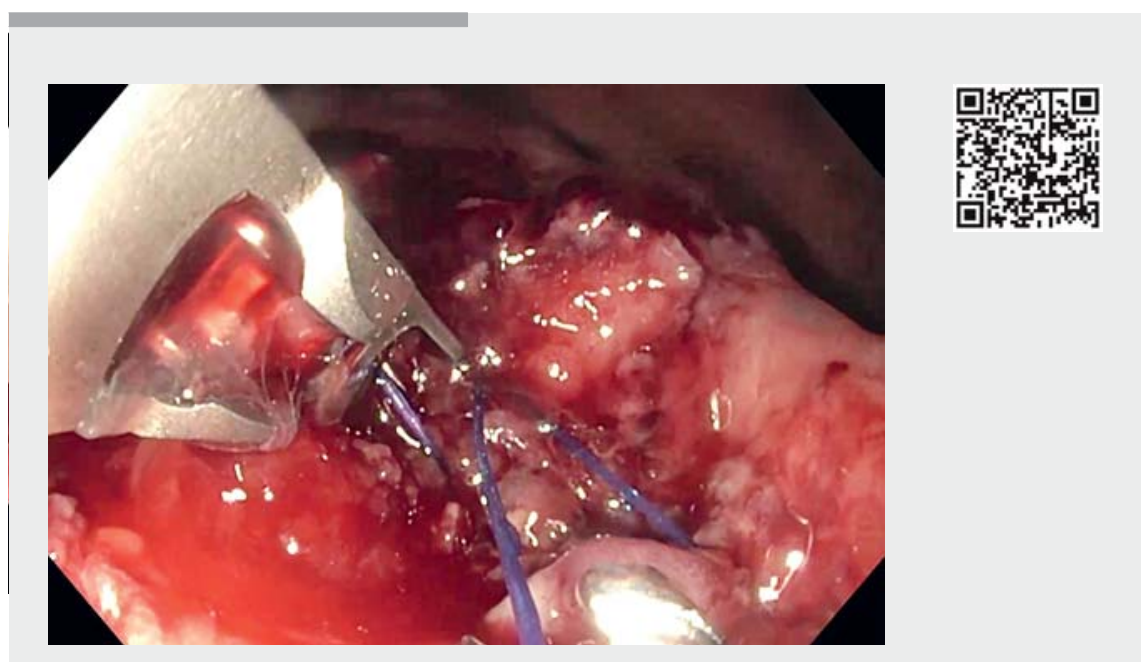

$\checkmark$ Video 1 An endoscopic suture device is used to close the gastrocolic fistula. colonoscopy. There was also reflux of colonic content to the esophagus.

We rinsed the stomach and colon of contents and cleaned them with acetic acid as an antiseptic. The LAMS was removed with a snare. The fistula opening was then closed with full-thickness sutures using an endoscopic suturing device ( $\vee$ Video 1 ). We installed contrast in the stomach, but saw no more leakage to the colon. A temporary nasoenteral tube was inserted to allow feeding and improve the patient's nutritional state. After 2 weeks, we created a new EUS-G]. The previous gastrocolic fistula was seen to have closed. The patient improved and was discharged within a few days.

Even though a gastrocolic fistula is a serious complication of EUS-GJ, we were still able to manage this patient endoscopically with closure of the fistula and redo EUS-G].

Endoscopy_UCTN_Code_TTT_1AS_2AG

\section{Competing interests}

Pham KDC has received lecture fee from Boston Scientific.

The authors

Khanh Do-Cong Pham ${ }^{1,2}$, Roald Flesland Havre $^{1}$

1 Department of Medicine, Haukeland University Hospital, Bergen, Norway

2 Department of Clinical Medicine, K1, University of Bergen, Norway

\section{Corresponding author}

\section{Khanh Do-Cong Pham, MD}

Section of Gastroenterology, Department of Medicine, Haukeland University Hospital, Jonas Lies vei 65, 5051 Bergen, Norway phamkdc@gmail.com

\section{References}

[1] Itoi T, Baron TH, Khashab MA et al. Technical review of endoscopic ultrasonographyguided gastroenterostomy in 2017. Dig Endosc 2017; 29: 495 - 502

[2] Chen Y-I, Kunda R, Storm AC et al. EUSguided gastroenterostomy: a multicenterstudy comparing the direct and balloon-assisted techniques. Gastrointest Endosc 2018; 87: 1215 - 1221

\section{Bibliography}

Dol https://doi.org/10.1055/a-0871-1629

Published online: 1.4.2019

Endoscopy 2019; 51: E169

(C) Georg Thieme Verlag KG

Stuttgart · New York

ISSN 0013-726X 